\title{
1 Behavioral flexibility of vervet monkeys in response to climatic and social variability
}

3 Richard McFarland ${ }^{\mathrm{a},{ }^{*}}$, Louise Barrett $^{\mathrm{a}, \mathrm{b}}$, Ria Boner $^{\mathrm{c}}$, Natalie J Freeman ${ }^{\mathrm{b}, \mathrm{c}}$, S Peter Henzi $^{\mathrm{b}, \mathrm{c}}$

5 aBrain Function Research Group, School of Physiology, Faculty of Health Sciences,

6 University of the Witwatersrand, Johannesburg, South Africa

$7 \quad{ }^{b}$ Department of Psychology, University of Lethbridge, Lethbridge, Canada

$8{ }^{\mathrm{c}}$ Applied Behavioural Ecology and Ecosystem Research Unit, University of South Africa,

9 Johannesburg, South Africa

10

11 * Correspondence: R. McFarland, School of Physiology, University of the Witwatersrand, 7

12 York Road, Medical School, Parktown, Johannesburg 2193, South Africa. E-mail address:

13 richard.mcfarland@ wits.ac.za; Tel: +27(0) 715999709.

14

15 Text pages $=14$, Bibliography pages $=5$, Figures $=2$, Tables $=2$, ESM Tables $=2$

16

17 Abbreviated title: Behavioral flexibility of vervet monkeys

18

19 Keywords: Activity; Ambient temperature; Chlorocebus pygerythrus; Mating season; Time-

20 budget

21

22 Grant sponsorship: This research was supported by a Claude Leon Fellowship awarded to

23 R.M, NSERC (Canada) Discovery grants to L.B and S.P.H, and a NRF (South Africa) grant 24 to S.P.H. 


\section{Abstract}

Responses to environmental variability sheds light on how individuals are able to survive in a particular habitat and provides an indication of the scope and limits of its niche. To understand whether climate has a direct impact on activity, and determine whether vervet monkeys have the behavioral flexibility to respond to environmental change, we examined whether the amount of time spent resting and feeding in the non-mating and mating seasons were predicted by the thermal and energetic constraints of ambient temperature. Our results show that high temperatures during the non-mating season were associated with an increase in time spent resting, at the expense of feeding. Cold temperatures during the non-mating season were associated with an increase in time spent feeding, at the expense of resting. In contrast, both feeding and resting time during the mating season were independent of temperature, suggesting that animals were not adjusting their activity in relation to temperature during this period. Our data indicate that climate has a direct effect on animal activity, and that animals may be thermally and energetically compromised in the mating season. Our study animals appear to have the behavioral flexibility to tolerate current environmental variability. However, future climate change scenarios predict that the time an animal has available for behaviors critical for survival will be constrained by temperature. Further investigations, aimed at determining the degree of behavioral and physiological flexibility displayed by primates, are needed if we are to fully understand the consequences of environmental change on their distribution and survival. 
The trade-offs involved in balancing energy and time budgets have long been a focus

of behavioral research. Among primates, the constraints imposed by intense sociality add an extra layer of complexity, as animals must trade off the benefits of group living (e.g., protection from predators) against the costs of competing within these groups for resources. Animals must also make compromises between different activities, such as feeding, resting socializing and moving, that reflect the attempt to maintain a positive energy balance while remaining coordinated with their conspecifics. In many cases, the trade-offs between different maintenance activities have been shown to reflect differences in resource abundance and quality, which dictates the amount of time that must be devoted to feeding, which then necessarily limits the amount of time available for other activities (Dunbar et al., 2009). In particular, the ability to engage socially with others has been shown to have consequences for both long- and short-term survival (Silk et al., 2009, 2010; Schülke et al., 2010; McFarland and Majolo, 2013). Social behaviors like grooming may also play a role in maintaining group cohesion over time, whereas a lack of social maintenance may result in groups becoming destabilized, leading to group fission (Henzi et al., 1997) and the potential loss of sociality benefits. Time available to rest has often been considered simply as a 'reserve' of time left over after other essential activities have been fulfilled (Dunbar, 1992). More recently, two separate forms of resting have been identified (e.g., Dunbar et al., 2009): 'free' resting time, defined as a reserve of time that can be converted into additional feeding, moving or socializing, and 'enforced' resting time, defined as the time required for thermoregulation and digestion. Due to the importance of thermoregulation and digestion, constraints on available resting time may have consequences for a species' ability to exist in particular habitats (Korstjens et al., 2010).

Given potential thermoregulatory constraints, it is clear that climate, namely ambient temperature and rainfall, may pose a very direct constraint on activity, in addition to its 
impact on the quality and distribution of available food resources (e.g., Del Grosso et al.,

71 2008), and hence the amount of time an animal needs to spend feeding to fulfill its energetic

72 requirements. The "thermoneutral zone" is defined as the range of environmental temperatures within which an animal's metabolic rate and evaporative heat loss is minimal

74 (Gordon, 1985). For primates, the thermoneutral zone is approximately 25 to $30^{\circ} \mathrm{C}$ (Elizondo, 1977). The maintenance of homeothermy in primates involves a combination of both autonomic and behavioural processes, where behavioural changes should be used first as a means to conserve the water and energy required for autonomic processes.

To date, the impact of direct climatic constraints on activity budgets has received little attention. We do know that, at high temperatures, some studies have revealed that animals tend to spend more time resting (Stelzner, 1988; Hill, 2006; Campos and Fedigan, 2009; Korstjens et al., 2010; Sato, 2012; Majolo et al., 2013), and that resting and shade-seeking are critical for thermoregulation (e.g., Campos and Fedigan, 2009): high heat load can cause severe dehydration and potentially fatal hyperthermia (Taylor, 1970). In contrast to the reduced demand for shade-seeking and resting in colder temperatures, the energetic demands of thermoregulation and digestion are higher in cold conditions (Satinoff, 2011), meaning more time needs to be spent feeding (Satinoff, 2011; Majolo et al., 2013) relationships with conspecifics, which is also likely to detract from their time available to

89 feed and rest. Other forms of social demand, such as mating, may also constrain activity, 90 especially among seasonal breeders where mating effort is concentrated into a short period. 91 Among these species, males in particular can spend significant amounts of time competing 92 for and mate-guarding females (Henzi and Lucas, 1980; Muller and Wrangham, 2009). If this 93 occurs at the expense of feeding and resting, it may cause them to become thermally and 
energetically compromised. Females may also be compromised due to time constraints imposed on them by male socio-sexual behavior.

Future climate change scenarios predict that, over the next 100 years, South Africa will be exposed to increased aridity and higher annual temperatures (Midgley et al., 2001). This in turn is expected to have a significant impact on species survival and distribution (Erasmus et al., 2002; Hoffman et al., 2009; Korstjens et al., 2010). Here, we explore direct climatic effects on the on activity of wild vervet monkeys (Chlorocebus pygerythrus), during both the non-mating and mating seasons, as a means of assessing how animals prioritize behavior and whether they possess sufficient behavioral flexibility to adjust their activity budget in response to competing demands. As we will show, this investigation is particularly relevant to vervet monkeys living below the equator, in a semi-desert habitat, as they experience a highly variable seasonal climate. Given that (i) our study population in the semiarid Karoo is at the most southerly limits of the vervet distribution and (ii) is a challenging habitat for such a water-dependent species (McDougall et al., 2010), it becomes pertinent to assess the scope and limits of their behavioral flexibility in response to current climatic fluctuations.

\section{During the non-mating season, we predicted that (i) higher ambient temperatures} would be associated with increased resting time, in order to reduce heat load and water loss, whereas feeding would be prioritized at cold temperatures to fulfill the increased energetic demands of thermoregulation. During the mating season, we predicted that (ii) both males and females would become thermally and energetically compromised compared to the nonmating season because of the additional time-constraints imposed by socio-sexual behavior. We therefore predicted that (iii) time spent resting and feeding by each sex would be unresponsive to temperature during this period. In all our analyses, we controlled for the effects of estimated food abundance and group size on activity patterns, allowing us to test 
the relative importance of climatic and ecological factors on activity patterns. That is, we took into account the fact that, when food abundance is low and group size is larger, more time is expected to be spent searching for food due to increased feeding competition (i.e. rates of aggression and patch depletion: Janson, 1988; Isbell 1991) and that, when group sizes are larger, more time is expected to be spent socializing as more social relationships need to be managed to maintain group cohesion (Dunbar, 1991; Lehmann et al., 2007).

\section{METHODS} RBM and RST) of wild vervet monkey living on the Samara Private Game Reserve in the

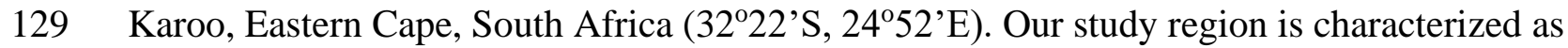
semi-arid riparian woodland, where our study animals feed predominantly on seeds, flowers, leaves, berries, gums and insects. For more details of their diet, see Pasternak et al. (2013). Vervet monkeys live in multi-male, multi-female societies (e.g., Isbell et al., 1991). Females are philopatric and males tend to emigrate from their natal group at the onset of puberty. Vervet monkeys are seasonal breeders and increased rates of male migration are typically observed at the onset of the mating season (Henzi and Lucas, 1980). During the mating season, males compete for access to mating opportunities with females.

138 (males $=4$ to 5 years; females $=3$ to 4 years) group members. Over the entire study period,

139 the average group sizes of RBM and RST were 26 and 36 adult and sub-adult animals,

140 respectively. Relatively small yearly changes in average group size were observed (ranges:

$141 \mathrm{RBM}=23$ to $30 ; \mathrm{RST}=34$ to 38 ; mean rate of change: $\mathrm{RBM}$ and $\mathrm{RST}= \pm 3$ animals/year)

142 suggesting that normal growth cycles (i.e., maturation of juveniles) and inter-birth intervals

143 were consistent across the study period. A larger degree of monthly variability in group sizes 
144 (ranges: $\mathrm{RBM}=17$ to $36 ; \mathrm{RST}=31$ to 44 ) was likely the result of fluctuations in rates of

145 male migration. The mating season in this region typically falls between April and June,

146 while the birth season typically falls between November and January. The hottest and wettest

147 time of the year is from November to March and the coldest and driest time of the year occurs

148 between June and August. All study animals were habituated to the presence of human

149 observers, were individually recognizable, and lived on a completely natural diet (Pasternak

150 et al., 2013). This study was entirely observational and did not affect the welfare of our study

151 animals.

152 Instantaneous scan sampling methods (Altmann, 1974) were used to collect data on

153 the activity time budgets of all adult and sub-adult group members from the two groups. Scan

154 data were collected every thirty minutes from all individuals that could be located within a

155 ten-minute time window. The activity of each subject was recorded as falling into one of five

156 mutually exclusive categories: i) Resting: when an animal was stationary without feeding or

157 socializing, ii) Feeding: when an animal was consuming food, iii) Moving: when an animal

158 was moving without feeding, iv) Socializing: when an animal was involved in allo-grooming,

159 v) Other: when an animal was involved in aggressive, mating or play behavior. Any given

160 animal was sampled only once within each scan. Across the four year study period, a total of

16150,591 and 61,381 scans were collected from RBM and RST, respectively. Group censuses

162 were taken daily to provide information on group size.

163 Climate data for the entire study period were available from a local weather station

$164\left(32^{\circ} 12^{\prime} \mathrm{S}, 24^{\circ} 33^{\prime} \mathrm{E}\right)$, which provided information on daily ambient temperatures $\left({ }^{\circ} \mathrm{C}\right.$ : mean,

165 maximum and minimum), relative humidity $(\%)$ and rainfall $(\mathrm{mm})$. Of the 865 days on which

166 we collected behavioral data, climate data were unavailable for 158 days, leaving 707 days of

167 observation as the focus of our analysis. 
169 climatic zones - have been shown to be positively correlated with rainfall (e.g., Del Grosso et

170 al., 2008). Several studies specific to our study region (i.e., the Karoo, Eastern Cape) have

171 also demonstrated positive correlations between vegetation abundance and rates of rainfall

172 (e.g., Hoffman et al., 1990; du Toit, 2002). Therefore, because we did not directly collect

173 food abundance data over the entire study period, we used rainfall as a proxy for monthly

174 food abundance (e.g., Coe et al. 1976; Barton et al., 1992; Hill et al., 2003). Since there is a

175 time-lag in the effect that rainfall has on vegetation biomass, and hence the abundance of

176 food available, we used two-month cumulative rainfall as an estimate of food abundance

177 (e.g., Barton et al., 1992).

\section{Data analysis}

We calculated, at the group level, the proportion of scans collected each day that our subjects spent resting, feeding, moving and socializing. This was calculated separately for males and females. We ran a series of generalized linear mixed models (GLMMs) to explore the effect of climatic variability on activity. The following analyses were repeated independently on males and females for both the non-mating and mating seasons. We entered either the proportion of time spent resting, feeding, socializing or moving as our dependent

187 variables. We applied an arcsine transformation to all our dependent variables to improve

188 normality. Our five climatic variables (mean, maximum and minimum ambient temperatures, rainfall and relative humidity) were all highly inter-correlated (all $P<0.001$ ), with the exception of minimum ambient temperature and relative humidity $(P=0.14)$. Mean ambient

191 temperature was positively correlated with maximum and minimum ambient temperatures

192 and rainfall, and negatively correlated with relative humidity. Therefore, of our five climatic 
193 variables, we entered only mean daily ambient temperature as an independent variable into

194 our model. Estimated monthly food abundance and group size were also entered as

195 independent variables. We entered the number of daylight hours for each scan day, and the

196 month of the year as control fixed factors in order to account for potential seasonal changes in

197 activity patterns (e.g., Hill et al., 2003). We entered the day of the scan nested inside group

198 ID as random factors to control for the non-independence and clustering of our dataset

199 (Pinheiro and Bates, 2000; Tabachnick and Fidell, 2007). Scans were collected from both

200 groups on the same day.

This 'full model' approach allowed us to explore the effect that our independent

variables had on our dependent variables, whilst controlling for the effects of our control

variables. For the sake of brevity, we discuss only those results directly related to our predictions. All analyses were performed in STATA v10 Software (StataCorp, 2007). See

Tables 1 and 2 for details of the effects of temperature, estimated food abundance and group size on the four main activity categories (i.e., resting, feeding, socializing and moving). See the electronic supplementary material for full GLMM results (Tables S1 and S2).

\section{RESULTS}

\section{Seasonal trends in climate and activity}

Over the four-year study period, mean ambient temperatures ranged from $-5.8^{\circ} \mathrm{C}$ to 42.1 $1^{\circ} \mathrm{C}$. The summer months (November to March) can be characterized as receiving higher

213 ambient temperatures, rainfall and relative humidity compared to the winter months (June to

214 August: Fig. 1). Both the non-mating and mating seasons showed large ranges in mean

215 ambient temperature (non-mating season $=3.7^{\circ} \mathrm{C}-30.3^{\circ} \mathrm{C}$; mating season $=3.8^{\circ} \mathrm{C}-24.6^{\circ} \mathrm{C}$ )

216 and estimated food abundance (non-mating season $=0.25 \mathrm{~mm}-128.53 \mathrm{~mm}$; mating season $=$

$2177.36 \mathrm{~mm}-142.49 \mathrm{~mm})$. High and low temperatures were observed in both the non-mating 
218 (highest $=42^{\circ} \mathrm{C}$, lowest $=0^{\circ} \mathrm{C}$ ) and mating season (highest $=37^{\circ} \mathrm{C}$, lowest $=0^{\circ} \mathrm{C}$ ). The amount

219 of time spent feeding was highly variable across the year (Fig. 2), ranging from

220 approximately $20 \%$ of the day in the hot, wet summers, to over $40 \%$ of the day in the cold,

221 dry winters. Conversely, the amount of time spent resting was highest in the summer ( 45\%),

222 and lowest in the winter $(\sim 30 \%)$. The time spent moving or socializing was less variable,

223 with time spent moving ranging between $20 \%$ and $30 \%$ of the day across the year, while time

224 spent socializing consistently accounted for less than $10 \%$ of the day across the year. The

225 seasonal patterns we observed in estimated food abundance, feeding time and stages of

226 reproduction (Fig. 2), support the view that vervet monkeys synchronize their reproduction to

227 make sure they have access to sufficient resources to succeed (Lee, 1987; Butynski, 1988).

The non-mating season

Insert Figs.

1 and 2

In support of our prediction, a significantly larger proportion of time was spent resting

at higher temperatures, compared to lower temperatures for both males and females in the

non-mating season (Table 1a). A significantly larger proportion of time was spent feeding in

lower temperatures compared to higher temperatures for both males and females (Table 1b).

233 The proportions of time spent feeding and moving were unrelated to estimated food

234 abundance for both males and females (Tables 1b, d). Similarly, the proportion of time spent socializing was unrelated to the size of the group for both males and females (Table 1c).

In support of our prediction, the proportion of time spent resting was unrelated to temperature for both males and females in the mating season (Table 2a). Similarly, the proportion of time spent feeding was unrelated to temperature for both males and females 
estimated food abundance (Table $2 b$ ), they spent a significantly smaller proportion of time moving when estimated food abundance was high (Table 2d). In partial support of our prediction, males, but not females, spent a significantly larger proportion of time socializing when group sizes were larger (Table 2c).

\section{DISCUSSION}

Vervet monkeys in our study population spent more time resting when temperatures

were high, and did so at the expense of feeding. When temperatures were cold, more time was spent feeding at the expense of resting. These findings are congruent with the suggestion that animals prioritize staying cool in hot periods to reduce heat load and water loss, and consume more food in cold periods to satisfy the increased energetic demands of thermoregulation and digestion.

Although it has been argued frequently that time spent resting is a 'reserve' of spare time that can easily be given over to feeding during periods of increased energetic demand, this fails to recognize the importance of resting time for behavioral thermoregulation.

Although it has been suggested that, in baboons, resting and shade-use are used only opportunistically (Hill, 2006) - as the priority is presumed to always be feeding - our results indicate that, for vervet monkeys, the importance of resting is so strong that resting is prioritized over feeding at high temperatures. Potential differences between these two species

262 in their ability to tolerate heat exposure might be explained by the smaller body mass of vervet monkey compared to baboons, which makes them more labile to changes in ambient temperature. Baboons, for example, have been shown to tolerate much higher heat loads than expected (Brain \& Mitchell 1999; Mitchell et al. 2009).

267 indirectly affects activity through its determination of habitat productivity and food 
268 abundance (e.g., Clutton-Brock, 1977; Wrangham, 1980). In our study, however, the direct

269 impact of climate (i.e., mean ambient temperature, which was positively correlated with

270 rainfall and negatively correlated with humidity) was the most influential factor in predicting

271 the amount of time an individual had available to rest and feed. When controlling for the

272 effect of ambient temperature, we found no evidence that estimated food abundance or the

273 size of the group was related to the time spent feeding or resting. These findings are

274 consistent with previous conclusions made on the importance of the thermal environment in

275 predicting activity patterns in primates (e.g., Hill, 2006; Korstjens et al., 2010).

We found that, in the mating season, time spent resting and feeding was unrelated to

277 temperature, suggesting that individuals were not adjusting their behavior to prioritize

278 thermoregulatory and energetic efficiency. Instead, these results suggests that, due to the

279 necessary investment in socio-sexual behavior and its associated reproductive benefits, both

280 males and females were exposing themselves to higher heat loads than they would typically,

281 and were feeding less than their energetic requirements demanded. In contrast to the non-

282 mating season, estimated food abundance had a significant impact on activity in the mating

283 season. Both males and females spent more time moving when estimated food abundance

284 was low. This is congruent with the suggestion that individuals should be able to feed more,

285 relative to the time they spend searching for food, when food abundance is high (Janson,

286 1988). Curiously however, this relationship was only observed in the mating season, not in

287 the non-mating season. Our finding that climate constrains activity in the non-mating season,

288 but not the mating season, may help us explain these results. In the non-mating season,

289 feeding times were most strongly predicted by temperature, and were unrelated to estimated

290 food abundance. However, in the mating season, when individuals appear to behave

291 independently of climate (due to the importance of socio-sexual behavior), foraging

292 behaviors (i.e., feeding and moving) are more strongly predicted by estimated food 
293 abundance. This may also be due to the exponential decline in estimated food abundance in

294 the mating season (see Fig. 1), making animal activity more sensitive to food abundance

295 during this period.

In contrast to the suggestion that group size is a major determinant of social behavior

297 in primates (Dunbar, 1991), we found no relationship between the size of the group and the

298 proportion of time spent socializing. Although the robustness of the relationship between

299 grooming (the constituent of our social activity category) and group size, and its importance

300 to group cohesion, has recently been questioned (Grueter et al., 2013; but see Dunbar and

301 Lehmann, 2013), it is important to note that Dunbar's analyses were run at the level of the

302 population and species (Dunbar, 1991), and so may not necessarily apply to these fine-

303 grained differences within a given habitat and population. Alternatively, the absence of a

304 relationship between group size and social time may be a reflection of the unusually large

305 group sizes of vervet monkey observed during this study. As reviewed in Pasternak et al.

306 (2013), the large size of our study groups compared is likely to reflect the particular nature of

307 their habitat: our study groups occupy high quality riparian habitat, which is surrounded by

308 low quality habitat with a lack of water. This leads to a high density of vervet groups along

309 the river system, and seems to retard fission into smaller groups (as this would require

310 daughter groups to occupy the low quality areas beyond the river). Lehmann et al. (2007)

311 suggested that when primate group sizes are over 40, ecological pressures are more likely to

312 compromise the time available individuals have to groom. Our findings support this view.

313 In the mating season males, but not females, spent more time being social when group

314 sizes were larger. Although these findings fit with the hypothesis that larger group sizes

315 require more time to be devoted to grooming to enhance group cohesion (Dunbar, 1991), the

316 fact that this relationship was observed only in the mating season, and only in males, suggests

317 that the increase in grooming behavior is more likely a result of the increased prevalence of 
mating. In the mating season males tend to spend more time grooming females to improve mating opportunities (Gumert, 2007). Moreover, due to the higher frequencies of male-male competition in the mating season (Henzi and Lucas, 1980) - where dominant individuals tend to gain better access to females (Cowlishaw and Dunbar, 1991; Majolo et al., 2012) grooming is likely to play an important role in managing male-male conflict. For example, grooming is often exchanged by former opponents to reconcile the costs of aggression (Cheney and Seyfarth, 1989; McFarland and Majolo, 2011a,b). Therefore, when group sizes are larger in the mating season - in terms of both potential mating partners and competitors there is likely to be increased demand for social activity. The difficulty of monopolizing females in larger groups in the mating season (Cowlishaw and Dunbar, 1991) may also explain why females were able to spend more time feeding when group sizes were larger; as their activity was less constrained by male socio-sexual behavior. Concomitantly, animals would need to spend more time feeding when group sizes were larger due to overall increased rates of feeding competition (Henzi et al., 2013).

Taken together, our findings support the view that climate has a direct and significant impact on animal activity patterns. Climate clearly constrains the activity of vervet monkeys, and our results suggest that, at least within this region of their geographic distribution, they have the behavioral flexibility to respond to variability in temperature in order to fulfill their thermal and energetic demands. However, during the mating season both males and females

337 potentially appear to be thermally and energetically compromised, due to the increased

338 demand and importance of socio-sexual behavior. Future studies need to explore in more detail how the mating season affects physiological condition. A number of recent studies

340 have contributed our understanding of the cortisol stress response of primates during such

341 periods (e.g., Ostner et al., 2008; Higham et al., 2012; McFarland et al., 2013). Future

342 important avenues of research should include the assessment of body temperature patterns 
and body condition in response to environmental stress. Such data will provide an indication

344 of the thermoregulatory efficiency of a species or population, and assess whether they have

345 the ability to maintain homeothermy when stressed.

346 The current thriving distribution of vervet monkeys in the Eastern Cape (Pasternak et

347 al., 2013) indicates that our study animals' current environmental variability is within a range

348 that they are able to tolerate. However, climate change scenarios predict that the Karoo will

349 get increasingly hot and dry over the next 100 years (Midgley et al., 2001), which could

350 affect species distribution, threatening their survival (Erasmus et al., 2002; Hoffman et al.,

3512009 ; Korstjens et al., 2010). Korstjens et al. (2010) propose that a $2^{\circ} \mathrm{C}$ increase in ambient

352 temperature will demand an increase in 'enforced' resting time (i.e., for thermoregulation)

353 which will significantly constrain the time available for other important behaviors such as

354 feeding and socializing. Further investigation into whether a species has the physiological

355 (including behavioral) flexibility to deal with environmental stress - in terms of extreme heat

356 and cold, drought, food shortages and loss of favorable microclimates - are urgently needed

357 if we are to fully understand the consequences that a changing environment will have on its

358 distribution and survival.

359

360

\section{ACKNOWLEDGEMENTS}

361

We are very grateful to Sarah and Mark Tompkins for permission to work on Samara

362 Private Game Reserve. We would also like to thank Nicholas Ducheminsky, Nicola Forshaw,

363 Alena and Eric Matlock, Petra McDougall, Derek Murphy, Jessica Parker, Graham Pasternak,

364 Tom Rutherford, Jessica Sashaw, April Takahashi and Brittany Thomas for assistance in data

365 collection over the four year study period. 
367 Altmann J. 1974. Observational study of behavior: Sampling methods. Behaviour 49:227267.

369 Barton RA, Whitten A, Strum SC, Byrne RW, Simpson AJ. 1992. Habitat use and resource 370 availability in baboons. Anim Behav 43:831-844.

371 Butynski TM. 1988. Guenon birth seasons and correlates with rainfall and food. In: Gautier-

372 Hion A, Bourlière F, Gautier JP, Kingdon J, editors. A primate radiation: evolutionary

373 biology of the African guenons. Cambridge: Cambridge University Press. p 284-322.

374 Campos FA, Fedigan LM. 2009. Behavioural adaptations to heat stress and water scarcity in 375 white-faced capuchins (Cebus capucinus) in Santa Rosa National Park, Costa Rica. Am J 376 Phys Anthropol 138:101-111.

377 Cheney DL, Seyfarth RM. 1989. Redirected aggression and reconciliation among vervet 378 monkeys, Cercopithecus aethiops. Behaviour 110:258-275.

379 Clutton-Brock TH. 1977. Primate Ecology: Studies of Feeding and ranging Behavior in

380 Lemurs, Monkey and apes. London: Academic Press.

381 Coe MJ, Cumming DH, Phillipson J. 1976. Biomass and production of large African 382 herbivores in relation to rainfall and primary production. Oecologia 22(4):341-354.

383 Cowlishaw G, Dunbar RIM. 1991. Dominance rank and mating success in male primates. 384 Anim Behav 41:1045-1056.

385 Del Grosso S, Parton W, Stohlgren T, Zheng D, Bachelet D, et al. 2008. Global potential net 386 primary production predicted from vegetation class, precipitation, and temperature. Ecology $387 \quad 89: 2117-2126$.

388 Du Toit PCV. 2002. Modelling Nama Karoo subshrub dry matter production using climatic 389 variables: research in action. S Afr J Sci 98:541-542. 
390 Dunbar RIM. 1992. Time: a hidden constraint on the behavioural ecology of baboons. Behav $391 \quad$ Ecol Sociobiol 31:35-49.

392 Dunbar RIM. 1991. Functional significance of social grooming in primates. Fol Primatol $393 \quad 57(3): 121-131$.

394 Dunbar RIM, Lehmann J. 2013. Grooming and social cohesion in primates: a comment on 395 Grueter et al. Evol Hum Behav 34(6):453-455.

396 Dunbar RIM, Korstjens AH, Lehmann J. 2009. Time as an ecological constraint. Biol Rev $39784: 413-429$.

398 Elizondo R. 1971. Temperature regulation in primates. Int Rev Physiol 15:71-118.

399 Erasmus BF, Van Jaarsveld AS, Chown SL, Kshatriya M, Wessels KJ. 2002. Vulnerability of 400 South African animal taxa to climate change. Glob Chang Biol 8(7):679-693.

401 Gordon CJ. 1985. Relationship between autonomic and behavioural thermoregulation in the 402 mouse. Physiol Behav 34:687-690.

403 Grueter CC, Bissonnette A, Isler K, van Schaik CP. 2013. Grooming and group cohesion in 404 primates: implications for the evolution of language. Evol Hum Behav 34:61-68.

405 Gumert MD. 2007. Payment for sex in a macaque mating market. Anim Behav 74(6):16554061667.

407 Henzi SP, Forshaw N, Boner R, Barrett L, Lusseau D. 2013. Scalar social dynamics in female 408 vervet monkey cohorts. Phil Trans R Soc B 368(1618):20120351.

409 Henzi SP, Lycett JE, Piper SE. 1997. Fission and troop size in a mountain baboon population. 410 Anim Behav 53(3):525-535.

411 Henzi SP, Lucas JW. 1980. Observations on the inter-troop movement of adult vervet 412 monkeys (Cercopithecus aethiops). Fol Primatol 33(3):220-235. 
413 Higham JP, Heistermann M, Maestripieri D. 2013. The endocrinology of male rhesus

414 macaque social and reproductive status: a test of the challenge and social stress hypotheses.

415 Behav Ecol Sociobiol 67:19-30.

416 Hill RA. 2006. Thermal constraints on activity scheduling and habitat choice in baboons. Am

417 J Phys Anthropol 129:242-249.

418 Hill RA, Barrett L, Gaynor D, Weingrill T, Dixon P, Payne H, Henzi SP. 2003. Day length, 419 latitude and behavioural (in)flexibility in baboons (Papio cynocephalus ursinus). Behav Ecol 420 Sociobiol 53:278-286.

421 Hoffman MT, Carrick PJ, Gillson L, West AG. 2009. Drought, climate change and vegetation 422 response in the succulent karoo, South Africa. S Afr J Sci 105(1-2):54-60.

423 Hoffman MT, Barr GD, Cowling RM. 1990. Vegetation dynamics in the semi-arid eastern 424 Karoo, South Africa: the effect of seasonal rainfall and competition on grass and shrub basal 425 cover. S Afr J Sci 86(7-10):462-463.

Isbell LA. 1991. Contest and scramble competition: patterns of female aggression and ranging behavior among primates. Behav Ecol 2(2):143-155.

428 Isbell LA, Cheney DL, Seyfarth RM. 1991. Group fusions and minimum group sizes in 429 vervet monkeys (Cercopithecus aethiops). Am J Primatol 25(1):57-65. Janson CH. 1988. Intra-specific food competition and primate social structure: a synthesis.

431 Behaviour 105:1-17.

432 Korstjens AH, Lehmann J, Dunbar RIM. 2010. Resting time as an ecological constraint on 433 primate biogeography. Anim Behav 79:361-374.

434 Lee PC. 1987. Nutrition, fertility and maternal investment in primates. J Zool 213(3):409435422.

436 Lehmann J, Korstjens AH, Dunbar RIM. 2007. Group size, grooming and social cohesion in 437 primates. Anim Behav 74(6):1617-1629. 
Majolo B, McFarland R, Young C, Qarro M. 2013. The effect of climatic factors on the activity budgets of a temperate primate, the Barbary macaque (Macaca sylvanus). Int $\mathrm{J}$ Primatol 34:500-514.

Majolo B, Lehmann J, de Bortoli Vizioli A, Schino G. 2012. Fitness-related beneftis of dominance in primates. Am J Phys Anthropol 147:652-660.

443 McDougall P, Forshaw N, Barrett L, Henzi SP. 2010. Leaving home: responses to water 444 depletion by vervet monkeys. J Arid Environ 74(8):924-927.

McFarland R, Majolo B. 2013. Coping with the cold: predictors of survival in wild Barbary macaques, Macaca sylvanus. Biol Lett 9: 20130428.

McFarland R, MacLarnon A, Heistermann M, Semple S. 2013. Physiological stress hormone 448 levels and mating behaviour are negatively correlated in male rhesus macaques (Macaca 449 mulatta). Anim Biol 63:331-341.

McFarland R, Majolo B. 2011a. Reconciliation and the costs of aggression in wild Barbary macaques (Macaca sylvanus): a test of the integrated hypothesis. Ethology 117: 928-937. McFarland R, Majolo B. 2011b. The importance of considering the behavioural form of reconciliation in studies of conflict resolution. Int J Primatol 34(1): 15-29. Midgley G, Rutherford M, Bond WJ. 2001. The heat is on... impacts of climate change on plant diversity in South Africa. National Botanic Institute, Cape Town, South Africa. Muller MN, Wrangham RW. 2009. Sexual coercion in primates and humans: an evolutionary 457 perspective on male aggression against females. USA: Harvard University Press.

458 Ostner J, Heistermann M, Schülke O. 2008. Dominance, aggression and physiological stress 459 in wild male Assamese macaques (Macaca assamensis). Horm Behav 54: 613-619. 460 Pasternak G, Brown LR, Kienzle S, Fuller A, Barrett L, Henzi SP. 2013. Population ecology 461 of vervet monkeys in a high latitude, semi-arid riparian woodland. Koedoe 55: 1-9. 
462 Pinheiro JC, Bates DM. 2000. Mixed effects models in S and S-PLUS. New York: Springer-

463 Verlag.

464 Satinoff E. 2011. Behavioral thermoregulation in the cold. Comprehensive Physiol 14:481-

465505.

466 Sato H. 2012. Diurnal resting in brown lemurs in a dry deciduous forest, northwestern

467 Madagascar: implications for seasonal thermoregulation. Primates 53:255-263.

468 Schülke O, Bhagavatula J, Vigilant L, Ostner J. 2010. Social bonds enhance reproductive 469 success in male macaques. Curr Biol 20: 2207-2210.

470 Silk JB, Beehner JC, Bergman TJ, Crockford C, Engh AL., et al. 2010. Strong and consistent 471 social bonds enhance the longevity of female baboons. Curr Biol 20(15):1359-1361.

472 Silk JB, Beehner JC, Bergman TJ, Crockford C, Engh AL, et al. 2009. The benefits of social 473 capital: close social bonds among female baboons enhance offspring survival. Proc Roy Soc 474 B 276: 3099-3104.

475 StataCorp. 2007. Stata statistical software: Release 10. Texas: Stata Press.

476 Stelzner JK. 1988. Thermal effects on movement patterns of yellow baboons. Primates

$477 \quad 29: 91-105$.

478 Tabachnick BG, Fidell LS. 2007. Using multivariate statistics. Boston: Pearson Education.

479 Taylor CR. 1970. II. Dehydration and heat: effects on temperature regulation of East African 480 ungulates. Am J Physiol 219:1136-1139.

481 Wrangham RW. 1980. An ecological model of female-bonded primate groups. Behaviour $482 \quad 75: 262-300$. 
484 Fig. 1 Mean monthly ambient temperatures (mean, maximum and minimum), relative

485 humidity and rainfall across the entire study period (January 2009 - March 2013)

486

487 Fig. 2 Seasonal patterns of (a) male and (b) female feeding and resting time in relation to

488 estimated food abundance, ambient temperature and phase of reproduction 